\title{
Are Protected Geographical Indications Evolving Due to Environmentally Related Justifications? An Analysis of Amendments in the Fruit and Vegetable Sector in the European Union
}

\author{
Andrea Marescotti ${ }^{1}$, Xiomara F. Quiñones-Ruiz ${ }^{2, *}{ }^{\oplus}$, Hanna Edelmann ${ }^{2} \oplus$, Giovanni Belletti ${ }^{1}{ }^{1}$, \\ Kristina Broscha ${ }^{2}$, Christine Altenbuchner ${ }^{2}$, Marianne Penker ${ }^{2} \mathbb{D}$ and Silvia Scaramuzzi ${ }^{3}$ \\ 1 Department of Economics and Management, University of Florence, 50127 Florence, Italy; \\ andrea.marescotti@unifi.it (A.M.); giovanni.belletti@unifi.it (G.B.) \\ 2 Department of Economics and Social Sciences, University of Natural Resources and Life Sciences, \\ Vienna (BOKU), 1180 Vienna, Austria; hanna.edelmann@boku.ac.at (H.E.); kristina_broscha@gmx.at (K.B.); \\ christine.altenbuchner@boku.ac.at (C.A.); marianne.penker@boku.ac.at (M.P.) \\ 3 Department of Agriculture, Food, Environment and Forestry, University of Florence, 50144 Florence, Italy; \\ silvia.scaramuzzi@unifi.it \\ * Correspondence: xiomara.fernanda.quinones-ruiz@boku.ac.at; Tel.: +43-1-47654-93339
}

Received: 20 February 2020; Accepted: 24 April 2020; Published: 27 April 2020

check for updates

\begin{abstract}
Protected designations of origin (PDO) and Protected geographical indications (PGI) in the European Union have been recognized through a sound legal framework for more than three decades. We are recently witnessing an increased number of amendments to the product specifications of registered PDO/PGI. This paper aims to understand how PDO/PGI for the fruit and vegetables product class have evolved. Until 31 December 2018, there were 379 PDO/PGI registered under the fruit and vegetables product class and 81 amendments approved. We designed a coding guideline to: (i) analyze all the amendments to the product specifications; (ii) identify the type of rules that were modified; (iii) find out whether the amendments resulted in more flexible or more restrictive rules, and (iv) the respective justifications given by producers. We designed a database to manage all the information. Overall, amendments brought more flexible rules (particularly in Italy and Spain), while France showed a more diversified situation. Concerning the justifications stated by producers for amending the product specification, market changes, available new technology, and strengthening product quality were the most important, while environmental concerns were less relevant. Then, we in-depth analyzed the amendments that were explicitly justified with environmental reasons. The analysis showed only a light movement towards more environment-friendly rules, although environmental justifications were often used "indirectly", as a means to achieve better marketing competitiveness, meeting new market demand and reducing production costs. These results seem consistent with previous studies, which indicated market forces as a primary motivation to amend product specifications.
\end{abstract}

Keywords: geographical indications; EU PDO/PGI; product specification; amendments; justifications; environmental sustainability

\section{Introduction}

Under the European Union (EU) regulatory system, Protected designations of origin (PDO) and protected geographical indications (PGI) are meant to safeguard product names based on the specific quality attributes derived from their geographical origin [1]. Natural conditions (e.g., weather, soils, 
altitude) and specific local knowledge and skills are essential factors in establishing the link to the origin $[2,3]$.

The registration of a PDO/PGI asks producers and their collective organizations to file an application where the link between the quality attributes of the product and its geographical origin is demonstrated, and to provide a product specification (PS), which contains the rules producers must comply with for using the PDO/PGI.

Evolving socio-economic conditions and changes in the biophysical environment may lead producers to amend PSs to tackle new challenges [4]. Nowadays, both scholars and policy makers consider food quality schemes as a tool for enhancing sustainability, including the environmental and social dimensions $[5,6]$. Pressures for modifying the contents of the PSs may come from environmental constraints, the evolution of the socio-economic context, advances in technological science and changes in the legal and political framework. Climate change can induce producers to introduce new plant varieties and production techniques [7]. The evolution of technology brings producers to adopt new production methods. Changes in markets and final consumers' demand may ask for new types of products and packaging, or the presence/absence of certain ingredients and additives. Changes in policies (such as phytosanitary and labelling rules) may oblige some adaptations in the production techniques and product quality characteristics [8,9].

Producers may also modify the contents of PSs in a more proactive way. In some cases, they aim at better positioning their product in some market segments, or better specifying its characteristics. In other cases, producers aim at introducing new production techniques to lower production costs $[10,11]$. Moreover, changes in market competition between producers can be another reason for adapting the PSs $[12,13]$.

When producers modify PS rules to allow for new production techniques and resources, or amend previous ones, they must also preserve the essential characteristics and protect the reputation of the PDO/PGI product. By re-defining and negotiating the PS, producers collectively manage the common reputation of the evolving PDO/PGI [12]. Therefore, amendments to the PS should be carried out carefully, as they might affect the intrinsic nature of the traditional and historically rooted products that consumers expect not to change.

Despite the extensive literature on PDO/PGI products, so far there are just a few case studies providing insights into PSs amendments [14]. Quetier et al. [15] noted that changes in the PS of PDO Roquefort have caused farmers to consider rangelands as a valuable resource and that by increasing the use of rangelands for sheep grazing and alimentation, this new strategy provided a more effective control of shrub and tree encroachment. Gueringer et al. [16] analyzed the link between the forage and farming systems, practices and biodiversity in the area of the PDO cheese St. Nectaire in the French Massif Central and observed how the PS for this PDO cheese changed, especially for the feeding of dairy cows. Still on cheeses, Colinet et al. [17] observed how Comté cheese producers introduced stricter rules over the time for silage, stocking rate, and the size limits of the cheese dairies. Bromberg [10] suggested that PSs modifications were "malleable to meet large-scale demand", reflecting the evolution of the market and final consumers, and increasing the distance between the original and traditional nature of the product and the new updated product available today. Arfini et al. [18] analyzed the evolution of the sustainability in the Parmigiano Reggiano PDO production system over the period 2000-2018 due to innovations in the product quality and the production process.

To our knowledge, there is no systematic analysis concerning PDO/PGI evolution observed through PSs amendments and focusing on the way PS rules change and their justifications. Thus, this paper aimed at understanding the evolution of PDO/PGI for a specific product class according to official EU classification, namely fruit, vegetables, and cereals fresh or processed (thereafter, fruit and vegetables), with a special focus on the role of environmental concerns in driving the amendments.

We have selected this product class as it is one of the most amended ones [14], it is dominated by unprocessed products with a more direct link to the agro-ecological farming system, and it is characterized by a consumer demand oriented towards health and environmental concerns, as the 
increase of organic production highlights. As pointed out by Morris and Kirwan [19], PDO/PGI protection has the potential to exert positive effects on the key components of ecological embeddedness and in particular, on how producers and other stakeholders address the environmental dimension of food production and the relationships with the market. PSs can incorporate rules that are directly or indirectly meant for preserving resources at the basis of product specificity [20-23], but there is a number of situations where the rules unintentionally exert negative effects on the environment [24].

The next section presents the methods supporting the analysis of the amendments of the selected product class. Section 3 displays first EU-wide empirical results on fruit and vegetables amendments. Section 4 is devoted to amendments explicitly motivated by environment-related concerns. Sections 5 and 6 portray the discussion and the conclusions respectively.

\section{Materials and Methods}

According to the EU Database of Origin and Registration (DOOR), which contains the official documents on agricultural products and foods registered, or awaiting possible registration as PDO and PGI [25], until 31 December 2018, there were 379 PDO/PGI registered products in the product class 1.6 (fruit, vegetables and cereals fresh or processed) and 81 approved amendments, mostly located in Italy, France and Spain respectively. To analyze the official documents listed on the DOOR database we developed coding guidelines that helped to systematically assess the changes in the geographical area, rules on the farming and processing level, and final product characteristics, which corresponded to the specific sections indicated by the legislation for amendment applications.

First, a critical review served to analyze all the amendment applications published in the Official Journal of the European Union, the official documents approving the amendment, and the original PS (found either on the DOOR database or from national Authorities). All the registered PDO/PGI of class 1.6 were scrutinized: out of the 379 PDO/PGI of the class, 72 filed a successful amendment application (with a total of 81 amendments, as some PDO/PGI amended their PS more than once).

To better specify the scope of our analysis, we focused on major (or non-minor) amendments as, according to Regulation (EU) No 1151/2012 (Article 53), "non-minor amendments affect the essential characteristics of the product, the defined geographical area, the link between the quality or characteristics of the product and the geographical environment, the link between a given quality, the reputation or other characteristics of the product and the geographical origin, or represent an increase in restrictions on trade in the product or its raw materials" [1]. Due to their lack of relevance, minor amendments were not considered in the analysis.

We designed a database to manage all the information stated in the amendments, which included the references to the document approving the amendment, the publication of the amendment application and the original and updated PSs. Additionally, to further understand the approved amendments, we pairwisely assessed the modifications (one amendment contained several modifications) based on the coding guidelines (e.g., inductive codes on geographical area and farming rules) (Table 1). Then, we identified the directionality of the amended rules (whether the modification implied stricter rules, more flexible rules, both directions, or just a clarification of the rules).

Moreover, we looked at the justifications for each of the 81 amendments and ranked the three most dominant ones through a pairwise assessment within the research group. It is worth noting that justifications (reasons) for amendments are specifically required both in Council Regulation (EC) No 510/2006 (Article 9) and the current Regulation (EU) No 1151/2012 (Article 53), where it is stated that "Applications shall describe and give reasons for the amendments requested" [1]. Justifications were classified into five categories:

- market: justifications related to the marketing strategies, sales activities, customers and consumers evolution, cost reduction;

- technology/research: need to update and to take advantage of the availability of new technologies, equipment, machines, research advances and results; 
- policy/legal: need to comply with mandatory regulations issued by the EU, national authorities, and professional organizations;

- identity/quality: need to keep or improve specific quality characteristics linked to traditions, strengthen the connection between the geographical area and the product;

- environmental sustainability and climate change: changes to PSs to reduce environmental impact, preserve biodiversity and landscape, promote organic production, and adapt to climate change.

We identified the stated justification(s) for each modification category (e.g., changes in farming or processing rules, see Table 1). Some amendments used only one justification for all the modifications, whilst others used different ones. Then, we ranked the justifications according to their relevance in the amendment application and assessed the dominant one(s) for the whole amendment.

This content analysis had to be particularly accurate, because directionality is sometimes uncertain, and producers do not always provide detailed and clear justifications. This depends also on the time when the amendment was filed (more recent amendments seem to be better justified), and on the country (some national authorities seem to ask for more detailed justifications than others do). In nine cases, no justifications were found. For all these reasons, the text analysis of the amendments was a double blinded analysis; in case of discrepancies, there was a consultation between the two researchers and a third researcher was requested for an additional blinded content analysis. If needed, experts in a specific field (e.g., agronomy) were consulted in order to better assess the directionality. As a second stage and after having a general overview of the amendments for the fruit and vegetables product class, we specifically searched for the amendments claiming environmental justifications for the modification brought to the PS (e.g., justified by environmental protection, nature, landscape conservation, or varying natural conditions such as climate change).

In the next section, we provided the results of the quantitative analysis on the dataset, supported with examples from the amendment documents of some PDO/PGI products.

Table 1. Categories and codes describing the modifications in the amendment documents.

\begin{tabular}{lll}
\hline Main Category & Sub-Category & Codes Describing Specific Modifications \\
\hline Geographical area & $\begin{array}{l}\text { Enlargement to a neighboring area; enlargement to a greater } \\
\text { extent (far or other geographical areas with other } \\
\text { characteristics); reduction of area; administrative change but } \\
\text { not change in area; further clarification without change }\end{array}$ \\
\hline Farming rules & Input & \begin{tabular}{l} 
Breeds/varieties/cultivars, chemical inputs, others \\
\cline { 2 - 3 } Processing rules
\end{tabular} \\
\cline { 2 - 3 } & Process & $\begin{array}{l}\text { Density and yields, season change, technological change, } \\
\text { further process change }\end{array}$ \\
\hline $\begin{array}{l}\text { Final product } \\
\text { characteristics }\end{array}$ & $\begin{array}{l}\text { Input from farm level, other inputs } \\
\text { Process }\end{array}$ & $\begin{array}{l}\text { Technology change/mechanization, length of process, } \\
\text { temperature, further process change }\end{array}$ \\
\hline
\end{tabular}

\section{The Evolution of PDO/PGI Product Specifications and the Environment}

\subsection{An Overview of the Amendments and Their Justifications}

Our elaborated database based on the DOOR data [25] included a total of 81 amendments approved for the fruit and vegetables class, with 72 amended products in the analyzed time frame (some of which with multiple amendments, altogether 24 PDO and 48 PGI).

Most of the amendments (43\%) were approved in Italy, followed by France (28\%) and Spain (18\%). Greece and Portugal registered 45 and 28 PDO/PGI, respectively, but filed only a few amendments (Table 2). The first amendment was approved in 2002. Within the 81 amendments, $73 \%$ were approved after 2012 (Figure 1). 
Table 2. Protected designation of origin (PDO) and Protected geographical indication (PGI)- registered products and non-minor amendments, “Fruit and vegetables class", 31.12.2018.

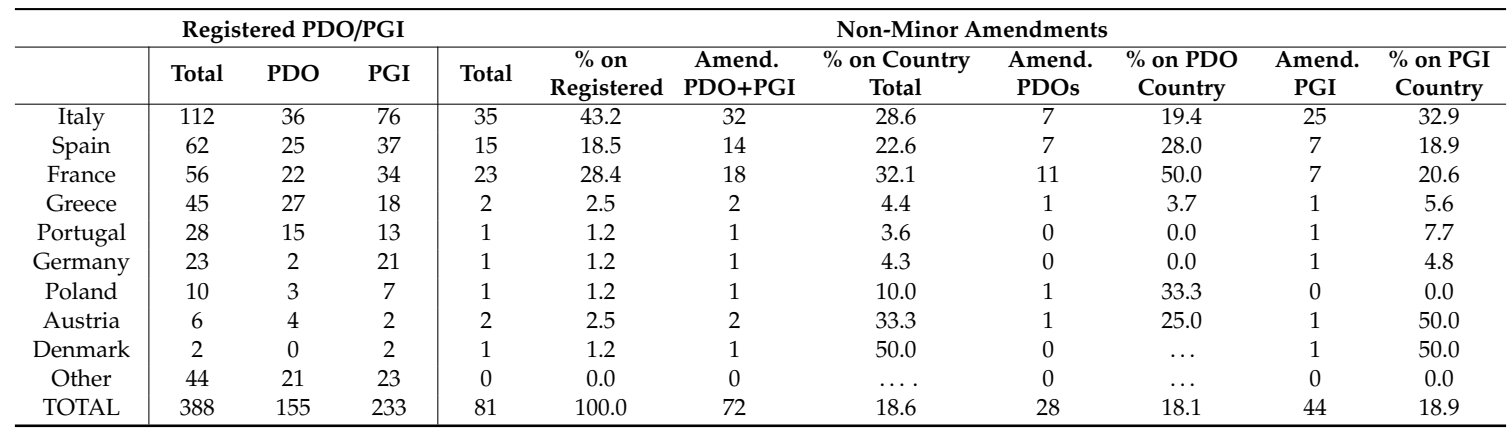

Note: Other countries (without amended PDO/PGI): United Kingdom (7), China (6 registered), Hungary (5), Croatia (4), Belgium (4), Netherlands (4), Czech Republic (3), Turkey (2), Thailand (2), Latvia (1), Sweden (1), Cyprus (1), Romania (1), Finland (1), Slovakia (1), Slovenia (1). Source: own elaboration based on the EU Database of Origin and Registration (DOOR) database [25].

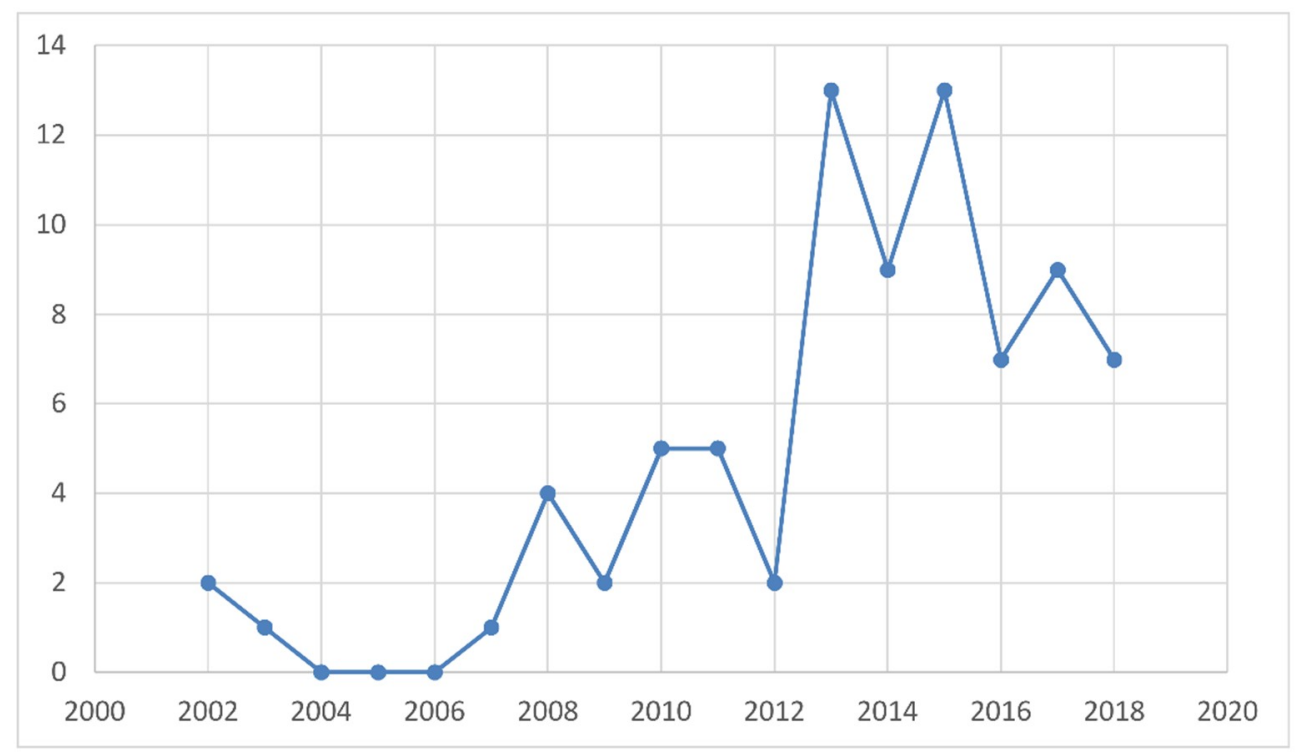

Figure 1. Number and year of approval of PDO/PGI amendments in the EU. Source: own elaboration based on the DOOR database [25].

Figure 2 presents the overall assessment of the directionality of each PDO/PGI amendment. This analysis was made after analyzing the modifications contained in each amendment (from the geographical area to the final product characteristics). Overall, amendments in Italy and Spain resulted in more flexible PSs. In France, the direction seemed less clear (for seven products rules have been both tightened and loosened).

Table 3 shows the first, second and third most important justifications according to the order/emphasis of the reasons stated in the official amendment documents. The market was the dominant first justification ( $41 \%$ of first justifications), followed by strengthening the identity/quality (31\% of first justifications), while the environment was mentioned as the first justification in only 5 cases ( $7 \%$ of the first justifications). Considering all the justifications independently of their rank, the justification categories market, technology/research and identity/quality each covered approximately $25 \%$, while the environment only accounted for $15 \%$. 


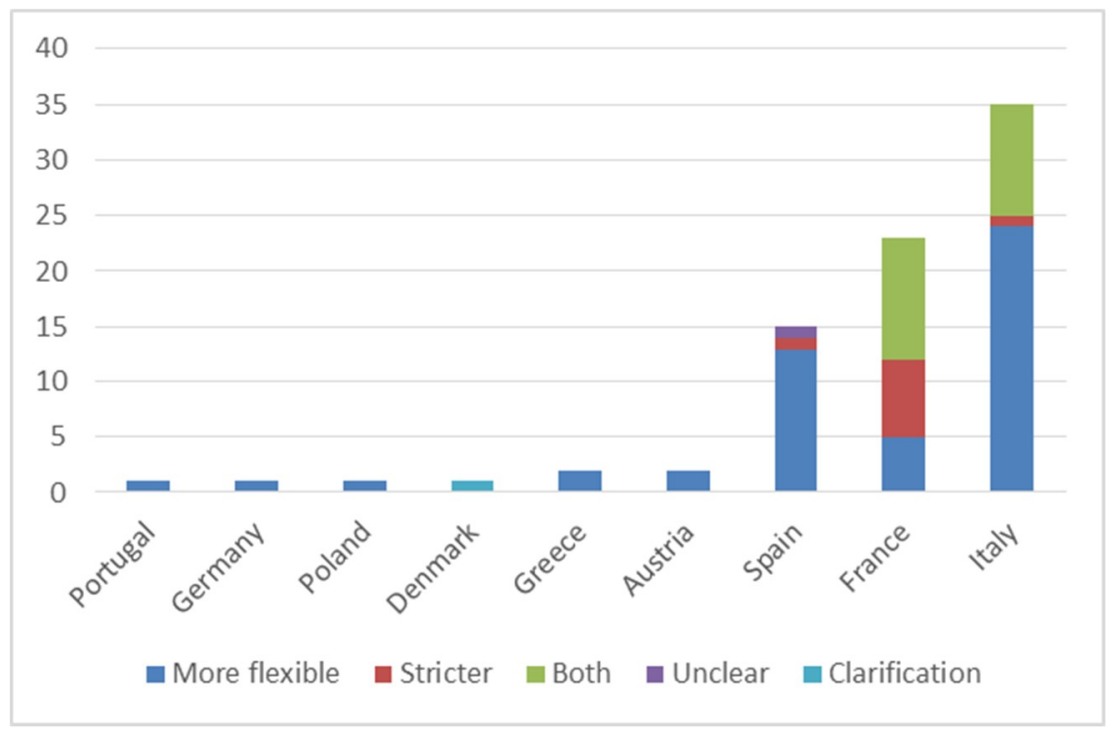

Figure 2. Overall directionality of the amendments per country. Source: own elaboration based on the DOOR database [25].

More specifically, the justifications belonging to the technology/research category were supported with the new results from research and/or the availability of new technology and machinery. Market justification was often related to the evolution of the consumers demand, new market requirements to comply with, new income opportunities and the cost/workload reduction. The category identity/quality mainly referred to the quality characteristics of the product and/or the area, traditions, the link between the region and the GI product or quality improvements. The policy/legal category contained amendments that had to be filed due to the need for adapting PSs to national or international legislation. The environment category was often related to the protection of natural resources, to landscape conservation and climate change.

Table 3. Justifications mentioned in the amendment applications in order of their importance (number of amendments analyzed: 81 ).

\begin{tabular}{ccccccccc}
\hline Order of importance & \multicolumn{2}{c}{ First } & \multicolumn{2}{c}{ Second } & \multicolumn{2}{c}{ Third } & \multicolumn{2}{c}{ Total } \\
\hline Categories & $\mathbf{n .}$ & $\mathbf{\%}$ & $\mathbf{n .}$ & $\mathbf{\%}$ & $\mathbf{n .}$ & $\mathbf{\%}$ & $\mathbf{n .}$ & $\%$ \\
\hline Market & 29 & 40.8 & 5 & 9.1 & 3 & 11.1 & 37 & 24.2 \\
Technology/research & 13 & 18.3 & 23 & 41.8 & 4 & 14.8 & 40 & 26.1 \\
Policy/legal & 2 & 2.8 & 5 & 9.1 & 8 & 29.6 & 15 & 9.8 \\
Environment & 5 & 7.0 & 11 & 20.0 & 7 & 25.9 & 23 & 15.0 \\
Identity/quality & 22 & 31.0 & 11 & 20.0 & 5 & 18.5 & 38 & 24.8 \\
\hline Total & 71 & 100.0 & 55 & 100.0 & 27 & 100.0 & 153 & 100.0 \\
\hline & Source: own elaboration based on the DOOR database [25].
\end{tabular}

In the following paragraphs, we analyze the main modifications for the main sub-categories, with special attention to the modifications justified by environmental reasons.

\subsection{Modifications of Geographical Area}

EU PDO/PGI products are anchored in a delimited geographical area described in the PS. Of the 35 fruit and vegetables amended in this section, 18 (51\%) of them enlarged the geographical area to neighboring regions. Justifications for the changes included arguments that the added territory had the same characteristics as the previous one, whilst others explicitly mentioned the need to meet increasing market demand (Berenjena de Almagro). Only one PDO/PGI enlarged the area to a greater 
extent, two PDO/PGI reduced the area and another two adapted the PS due to administrative changes (e.g., new names of municipalities). Only one amendment (Cítricos Valencianos) justified the need to enlarge the production area with climate change, that "has led to the development of ecosystems which are suitable for citrus production using the same growing methods and producing fruit of the same organoleptic quality".

\subsection{Modifications of Farming Inputs and Process}

In relation to the modifications of farming rules, in order to codify the information, we identified two main sub-categories (input and process) with seven codes (Figure 3).

In general, the modifications of PSs headed towards more flexible farming rules. In particular, many PSs loosened their rules of production to allow for a higher number of varieties, or an intensification of the production system by increasing the maximum number of plants per hectare or the output (yield).

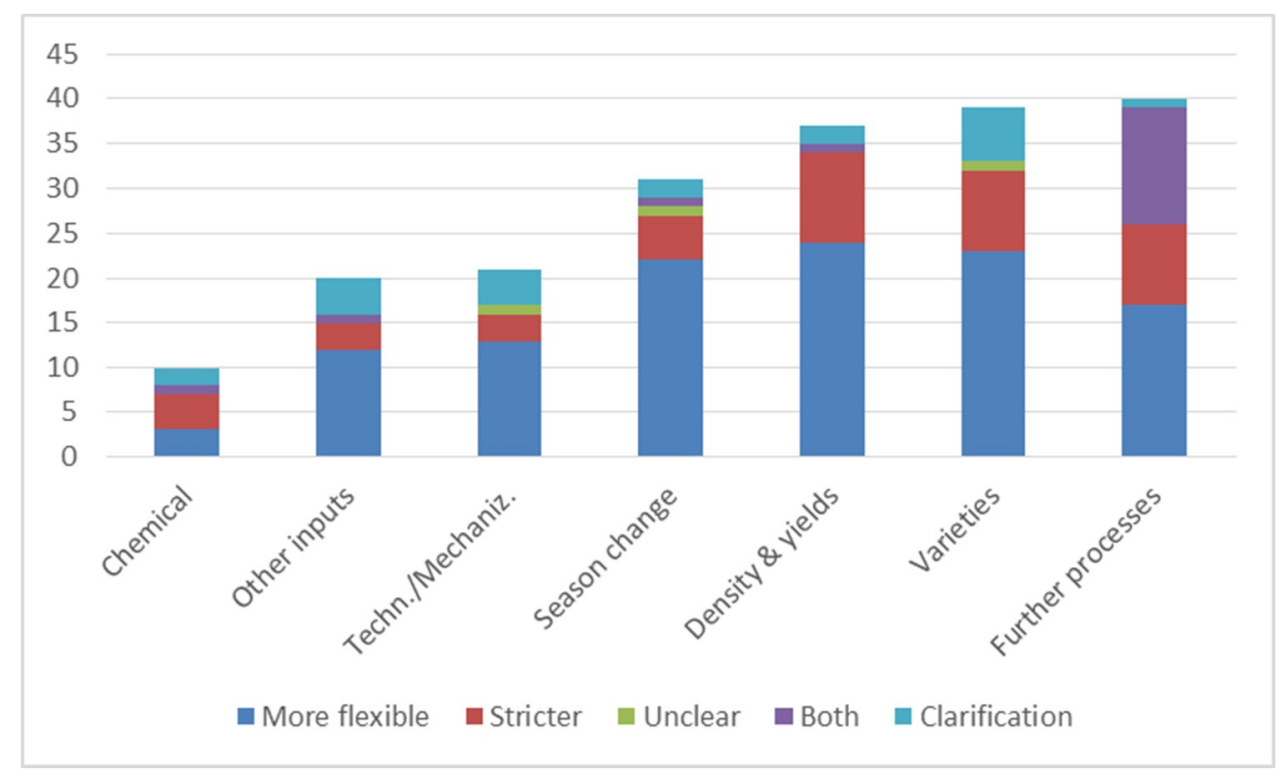

Figure 3. Modifications approved on the farming rules. Source: own elaboration based on the DOOR database [25].

Regarding changes in the farming rules, the most important justification was related to advances in technology and research (Table 4), which allowed new inputs (seeds, fertilizers), and production techniques promising increasing yields. The relevance of environmental justifications for farming rules was higher than the one for other categories. Ten amendments contained modifications with the environment as most the important justification. In particular, five amendments stated as a first justification environment-related reasons and another five stated changes in natural conditions (climate change). Overall, $16.5 \%$ of the modifications in farming rules were environmentally motivated (7\% across all categories). The need to preserve identity and final product quality characteristics was important too, coupled to market considerations. 
Table 4. Justification for the amendments in the farm level area.

\begin{tabular}{cccccccccc}
\hline Order of Importance & \multicolumn{2}{c}{ First } & \multicolumn{2}{c}{ Second } & \multicolumn{2}{c}{ Third } & \multicolumn{2}{c}{ Total } \\
\hline Categories & $\mathbf{n .}$ & $\mathbf{\%}$ & $\mathbf{n .}$ & $\mathbf{\%}$ & $\mathbf{n .}$ & $\mathbf{\%}$ & $\mathbf{n .}$ & $\mathbf{\%}$ \\
\hline Market & 13 & 21.7 & 3 & 9.7 & 0 & 0.0 & 16 & 16.7 \\
Technology/research & 22 & 36.7 & 10 & 32.3 & 1 & 20.0 & 33 & 34.4 \\
Policy/legal & 0 & 0.0 & 4 & 12.9 & 0 & 0.0 & 4 & 4.2 \\
Environment & 10 & 26.7 & 7 & 22.6 & 1 & 20.0 & 18 & 18.8 \\
Identity/quality & 15 & 25.0 & 7 & 22.6 & 3 & 60.0 & 25 & 26.0 \\
\hline Total & 60 & 100.0 & 31 & 100.0 & 5 & 100.0 & 96 & 100.0 \\
\hline & Source: own elaboration based on the DOOR database [25].
\end{tabular}

\subsubsection{Farming Rules-Input}

In this sub-category, the modifications affected plant varieties, the use of chemicals and other inputs.

There were 39 modifications concerning the use of varieties, 23 of which loosened the rules to extend the number of allowed plant varieties by introducing new ones, while two (Riz de Camargue and Chasselas de Moissac) established procedures to modify the list of varieties. In general, PDO/PGI producers increased the number of plant varieties to meet a new market demand (customers and final consumers) and to extend the length of the marketing campaign. In only one case (Cerezas de la Montaña de Alicante), new authorized varieties were justified by the need to tackle climate change. Overall, this may loosen the link to local varieties, which suffer from the competition with new, more performance-oriented and resistant varieties.

There were fewer modifications concerning the chemicals used. Only four amendment applications restricted, or further regulated the use of fertilizers. The Pommes et Poires de Savoie amendment prohibited the use of synthetic chemicals to protect the original characteristics of the soils, the Pommes de Terre de l'Île de Ré introduced a maximum limit for the addition of mineral nitrogen per year, and the Noix de Grenoble regulated the use of fertilizers. It is worth highlighting that these last two amendments were not justified by environmental concerns, but by technology evolution, and by the quality of the final product, respectively.

Finally, other inputs referred to farming rules that were not related to varieties or chemicals (e.g., quantity of water used for irrigation, organic fertilizers like compost). This category included 20 amended GIs out of 72. The modifications mainly moved towards the higher flexibility of the PS rules (12). In the case of the Greek Olive Konservolia Rovion for example, the amendment aimed at including the organic fertilizers in the PS was justified by the diffusion of organic production in the area. In the case of the apple Mela dell'Alto Adige, irrigation practices were made more flexible, and the option of complete weed control was introduced.

\subsubsection{Farming Rules—Process}

The subcategory farming rules-process deals with the modifications concerning the density/yields, season change, technology/mechanization, and further processes.

The modifications of the rules on density and yields described changes in either the number of plants, or the maximum allowed production per hectare. A total of 37 amendments altered the production rules concerning the density and yields. Of these, $65 \%$ of the amendments made rules more flexible, supposedly allowing for an increase in the output per area. Most of the justifications given in the amendments referred to the availability of new cultivation techniques and/or varieties, which made it possible to increase the maximum quantities per hectare without affecting the quality and identity of the final product. There were also 10 cases $(27 \%)$ where rules were made stricter, either for the need to better perform mechanical harvesting (Carciofo Spinoso di Sardegna), or to preserve the quality and the sugar content of the final product (Chasselas de Moissac). Only in the case of the Olives Noires de Nyons was there an explicit reference to the changing environmental conditions as a 
justification, stating that-among other justifications—“"the lack of any significant frost since 1985 has led to bigger trees producing larger crops".

With regards to season change, some PSs explicitly defined the timing of certain agricultural activities like harvesting, irrigation, planting, or pruning. The majority of amendments that altered this section made the timing more flexible: some PDO/PGI extended the harvesting period because of changing natural conditions (such as the Lentilles Vertes du Berry, La Bella della Daunia, Limone di Sorrento, Radicchio Variegato di Castelfranco). Other PDO/PGI changed the timing of other farming practices, due to an altered production system (the transition from the family farms to larger orchards in the Spanish Melocotón de Calanda), a reduction of the workload (extension of the irrigation period to simplify the harvest of the Noix du Périgord), or due to legal/institutional change (e.g., timing fixed by another authority: harvesting date fixed by the director of the National Institute of Origin and Quality (INAO) instead of the inter-ministerial order in the French Olives de Nîmes).

Modifications of rules on technology/mechanization referred to changes in technological means as well as production steps that were (not) allowed to be mechanized. In this section, $62 \%$ of the amendments allowed for a higher flexibility in terms of technology, and mechanical means. New harvesting techniques were accepted (e.g., Olives Noires de Nyons), machinery use was made more flexible (e.g., Pommes de Terre de l'île de Ré deleted the reference to the planting with a plotting machine because this method was outdated), or new cultivation techniques were introduced (e.g., for the cherry trees of the Ciliegia di Vignola).

Modifications regarding the further process change at farm level included agricultural practices that did not fit into one of the other sections. Examples were changed rules on specific processes such as ploughing and phytosanitary treatments (Lingot du Nord), washing and storage requirements at the farms (Olives de Nice), timing of quality controls and the temperature at the packaging facilities (Mâche Nantaise), or the no longer necessary ground cover under the apricot trees (Wachauer Marille). While $44 \%$ of these amendments gave producers more flexibility and therefore loosened their PSs, $23 \%$ tightened their rules.

\subsection{Modifications of Processing Rules}

Fifteen amendments were classified as the amendments modifying rules dealing with the further processing steps of fruits and vegetables. Five amendments dealt with preserved olives, two with beans and one with lentils, chestnut, potato, walnut, rice, pistachio, grapes, and tomato respectively.

The analysis of the amendments shows that most of the modifications aimed at changing some aspects of the production process (i.e., the technology or length of some operations) either to better preserve the quality of the final product, and/or to increase the flexibility of some technical operations. Only the Konservolia Rovion amendment mentioned the environment: “As a result of the development of organic farming since the year 2000 (70\% of olive groves planted with 'Konservolia Rovion' are now organically farmed), and the conversion of a substantial part of olive production to organic, caustic soda may no longer be used to remove the bitterness from the fruit. Instead, the bitterness is removed from organic olives in the traditional natural way, i.e., in tanks filled with a solution of sodium chloride".

\subsection{Modifications of Rules on Final Product Characteristics}

In Figure 4, the modifications concerning the characteristics of the final products are shown. All 72 products amended the final product characteristics, and six filed two or three amendments (three in France and three in Italy). The analysis categorized the modifications into nine codes.

Very few cases (five) were justified by environment-related reasons, and only two used it as the first justification (3.0\% of the total of the first justifications). The market (39.4\%) and product identity/quality (31.8\%) were the main first justifications stated by producers (Table 5$)$. 


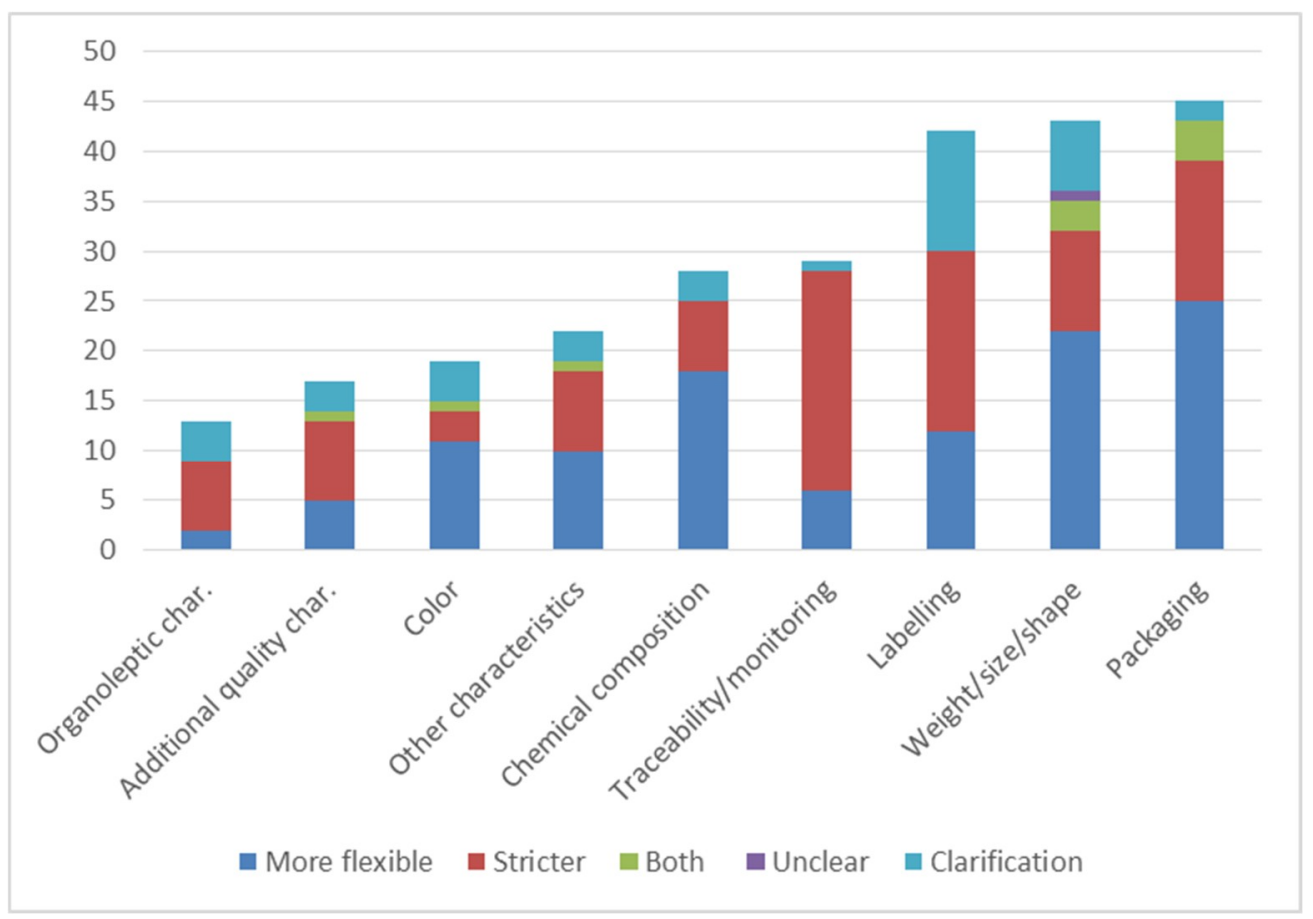

Figure 4. Major types of the changes approved in the final product characteristics. Note: Additional quality characteristics refer to all product attributes other than color, chemical composition, weight/size/shape, and organoleptic characteristics. Other characteristics correspond to all modifications in final product characteristics that could not be included in any of the other categories. Source: own elaboration based on the DOOR database [25].

Table 5. Justification for the modifications in the final product characteristics.

\begin{tabular}{ccccccccc}
\hline Order of Importance & \multicolumn{2}{c}{ First } & \multicolumn{2}{c}{ Second } & \multicolumn{2}{c}{ Third } & \multicolumn{2}{c}{ Total } \\
\hline Categories & n. & $\mathbf{\%}$ & $\mathbf{n .}$ & $\mathbf{\%}$ & $\mathbf{n .}$ & $\mathbf{\%}$ & $\mathbf{n .}$ & $\%$ \\
\hline Market & 26 & 39.4 & 6 & 18.8 & 0 & 0.0 & 32 & 31.1 \\
Technology/research & 11 & 16.7 & 8 & 25.0 & 0 & 0.0 & 19 & 18.4 \\
Policy/legal & 6 & 9.1 & 8 & 25.0 & 2 & 40.0 & 16 & 15.5 \\
Environment & 2 & 3.0 & 2 & 6.3 & 1 & 20.0 & 5 & 4.9 \\
Identity/quality & 21 & 31.8 & 8 & 25.0 & 2 & 40.0 & 31 & 30.1 \\
\hline Total & 66 & 100.0 & 32 & 100.0 & 5 & 100.0 & 103 & 100.0 \\
\hline
\end{tabular}

Source: own elaboration based on the DOOR database [25].

The modifications of the rules on the weight/size/shape, chemical composition as well as packaging mostly showed a trend towards more flexible rules, especially to meet the evolution of the market requirements, leaving producers more freedom to vary and adapt their product individually, but also with the risk of a loss of product specificity on the market, or of unfair internal competition phenomena (low-quality products expel the best ones from the PDO/PGI). Some PDO/PGI pursued an opposite strategy, strengthening their product identity by increasing the minimum level for the extrinsic quality characteristics, such as minimum size (e.g., Olive de Nice, Radicchio Rosso di Treviso, Noix de Grenoble).

In only a few cases the amendments were justified by environmental issues. For example, in order to make the compliance to the PS easier for organic production, the Riz de Camargue raised the maximum level of impurities in the final product, and the Pommes et Poires de Savoie, Mela dell'Alto Adige and Konservolia Rovion introduced more flexible rules on size. The changed climatic conditions justified some amendments. The Pommes de Terre de l'Île de Ré raised the maximum authorized 
dry matter content because of changes in the climate, while the Lentilles Vertes du Berry allowed the presence of more cracks in seeds because of the more frequent droughts in the area. The Carota dell'Altopiano del Fucino made the chemical composition of the product more flexible in order to reduce the nitrogen inputs, and to use agricultural water resources more responsibly.

The other more amended sections were labelling and traceability/monitoring, with most of the rules getting stricter after the amendments. Eighteen introduced stricter traceability or monitoring systems that included, for example, the keeping of registers, or certain declaration requirements (e.g., the Olives de Nice, Pommes de Terre de l'Île de Ré, Nocciola di Giffoni). The modifications in labelling concerned the requirement to use the EU PDO/PGI logo, stricter obligations on how to place and present the PDO/PGI's own logo (e.g., Asparago Bianco di Cimadolmo, Noix de Grenoble), or the mandatory use of stickers to guarantee traceability for each plant (e.g., $80 \%$ of the lemons of the Limone di Sorrento need to be labelled with a sticker). These amendments were not directly related to the environment.

\section{In-Depth Analysis of Environmentally Justified Amendments}

After an overview gained of all 81 amendments, we started to look in depth at those modifications on the geographical area, farming and processing, and final product characteristics, that producers explicitly justified with considerations linked to the environment.

We identified 21 amendments containing environment-related justifications (environmental sustainability, change in natural conditions such as climate, etc.). We carried out an in-depth analysis of the justifications stated in the texts, which we grouped into two categories. The first dealt with "reactive" amendments, where producers affirmed to modify the PS rules because of changed environmental conditions (climate change). The second included "proactive" amendments, those pecifically justified with-directly or indirectly-favoring the adoption of environment-friendly practices. Some amendments contained both environmentally reactive and proactive justifications.

\subsection{Reactive Amendments}

The first group included 12 PDO/PGI: Lentilles Vertes du Berry (FR), Radicchio Variegato di Castelfranco (IT), La Bella della Daunia (IT), Melon du Haut-Poitou (FR), Limone di Sorrento (IT), Cítricos Valencianos (ES), Melocotón de Calanda (ES), Pommes de Terre de l'île de Ré (FR), Marrone del Mugello (IT), Cerezas de la Montaña de Alicante (ES), Oignon doux des Cévennes (FR), Patata dell'Alto Viterbese (IT). These PDO/PGI amendments justified some PS modifications as a reaction to the changing natural conditions (weather/climate). They can be interpreted as "reactive" amendments, since they reported some observed change in natural conditions (often quoting climate change) in the production area. Therefore, the modifications brought to the PSs rules were in a way to adapt the rules to the new environmental conditions.

Most modifications affected the timing of certain farming practices, especially the date of harvesting or planting, for the removal of protective tunnels (Melon du Haut-Poitou), or anticipating the release date for consumption (Marrone del Mugello), since in recent years seasonal variations steadily brought forward the point at which fruits ripen and fall and changed the periods for thinning and bagging (Melocotón de Calanda).

Other modifications affected the product quality characteristics. Cerezas de la Montaña de Alicante added some cherry tree varieties, as the old ones were no longer fit due to the increase of temperatures in the production area. The Lentilles Vertes du Berry modified the maximum quantity of cracks in the product due to climate change, and for the same reason, the Pommes de Terre de l'Île de Ré raised the authorized dry matter content. Only one amendment modified the production area, as climate change brought ecosystem changes making surrounding areas which were previously excluded by the PS fit for production (Cítricos Valencianos). 


\subsection{Proactive Amendments}

The second group comprised proactive modifications that were explicitly justified by environmental protection or nature, and landscape conservation and improvement. In this proactive group, we identified 11 PDO/PGI: Carota dell'Altopiano del Fucino (IT), Arroz de Valencia (ES), Fasola Piękny Jaś z Doliny Dunajca (PL), Nocciola di Giffoni (IT), Oignons Doux des Cévennes (FR), Konservolia Rovion (GR), Limone Costa d'Amalfi (IT), Pommes et Poires de Savoie (FR), Mela Alto Adige (IT), Arroz del Delta del Ebro (ES), Patata dell'Alto Viterbese (IT).

Some modifications aimed at changing some farming input and/or practices towards more environmentally sustainable ones. The Arroz de Valencia admitted five new varieties of rice specifically meant for making cultivation more sustainable and more fit to be grown in a natural park. The Arroz del Delta del Ebro introduced a local rice variety better suited to the local climate and soil conditions, allowing for water saving and a reduction in the use of fungicides, "which makes it more sustainable for the environment". Moreover, this variety "maintains the balance between the agronomic model and the respect for and preservation of the Ebro Delta Natural Park". Furthermore, some growing techniques that enabled a reduction in water consumption were introduced as they were more respectful of the environment. The Carota dell'Altopiano del Fucino lowered the minimum betacarotene content in the final product to reduce nitrogen inputs, and to use agricultural water resources more responsibly, at the same time allowing for the use of additional cultivars and hybrids.

Another four amendments dealt with modifications made to ease the adoption of organic cultivation/production methods. The Mela Alto Adige now includes commercial category II fruit, provided that they were grown using organic methods. The Konservolia Rovion modified some PS rules to comply with organic production rules. Organic fertilizers were therefore included, as well as the possibility of removing olive bitterness using sodium chloride instead of caustic soda. The Pommes et Poires de Savoie presented a modification to extend the marketing categories for the fruit to cover category II to allow access to the PGI for organic products. Patata dell'Alto Viterbese modified some rules related to the ploughing or subsoiling in order to avoid plough pans, and the impoverishment of the soil's organic matter, which was recommended in organic farming and other environment and climate-friendly farming practices.

Other amendments also addressed soil protection. In the Nocciola di Giffoni amendment certain hazel groves can be grown with a higher growing density, being located on terraced land or slopes with a gradient of more than $15 \%$. It was stated that hazel cultivation also played an important role in soil protection and conservation: "there is an interaction between the greater planting densities found in more steeply sloping hilly areas and protection and conservation of the soil, which the dense planting of fruit trees by humans over the centuries has helped to maintain". The Pommes et Poires de Savoie presented a modification concerning the prohibition of synthetic chemicals to disinfect the soil "in order to promote cultivation practices that are less aggressive towards the environment and thus to protect the original characteristics of the soils [ ... ]". Moreover, as we have seen, some amendments brought to the Patata dell'Alto Viterbese PS aimed at safeguarding the quality of the soils and the better control of parasites, as suggested by environment-friendly farm practices.

With "a view to long-term sustainable agriculture and to maintaining production", the Oignons Doux des Cévennes prohibited the possibility to plant onions on parcels that had already been used for sowing in the same year, because of both the observed weakening of the quality of onion and for pest control.

Two amendments were specifically meant to enhance the landscape. In fact, Fasola Piękny Jaś $z$ Doliny Dunajca added in the PS sunflower plants as canes to support plants as "this method is increasingly popular among farmers because it has a greening effect and enhances the landscape". The case of the Limone Costa d'Amalfi is more articulated. The traditional technique of production, as described in the previous PS, is to grow the trees under trellises made of wooden posts, preferably chestnut. The amendment introduced the possibility to use, besides chestnut wood, "other materials compatible with the environment and countryside protection". The main justification was to reduce 
(fixed) production costs and thus providing an incentive to grow lemons in the area, but the concern was also to safeguard the local traditional landscape, which is a real attraction for tourism and therefore for local socio-economic development.

\section{Discussion}

This study systematically analyzed the evolution of PSs rules of an entire product class of PDO/PGI in the EU, trying to grasp the relevance of environment-related concerns in driving the amendments to PSs.

Our results showed that producers justified PSs modifications with market change, the strengthening of product identity and quality, new technologies or research, and only to a lesser extent with environmental reasons or changed policies.

These results are in line with the previous studies. Riccheri et al. [26], who carried out an extensive study on the relationships between the registration of PDO/PGI and the environment, showed how in many cases the primary motivation to look for protection has been economic: the protection was established to define a market niche linked to traditional and local production methods, and to obtain a price premium for the protected product. Furthermore, although the conservation of local heritage (e.g., land use, cultural landscapes) was a major concern for most products, Riccheri et al. [26] (p. 61) argued that "by contrast, only relatively few GIs were explicitly set up with the motivation to protect the local environment". This was also confirmed by the analysis carried out by Larson [27]. Again, Belletti et al. [28], investigating the relationship between PDO/PGI products and the environment through the analysis of olive oil PSs in the EU, noted how enforceable rules were virtually inexistent for soil management and irrigation, while approximately $20 \%$ of the reviewed PSs encompassed rules on phytosanitary and fertilization methods, and just under half of PSs suggested specific olive tree varieties and fixed maximum production limits. These findings were in line with the EU protection system outreach, "which is conceived as a market tool as opposed to an implement for environmental policy" [28] (p. 104).

Indeed, public policies, evolving consumer demands, wholesale and retail distributors' requests (in terms of quantity assurance, quality standardization, product and process certification) and the specific quality attributes, demanded by the food processing and manufacturing industry, have had a high impact on the agricultural production, and the organization of producers in the fruit and vegetable sector [29]. These trends also affected PDO/PGI fruit and vegetables, which may suffer from too rigid production rules as agreed in each PS, and too rigid and long procedures to rapidly adapting the PS contents. On the other side, stakeholders should also try to keep and strengthen the identity of the PDO/PGI product to feed its diversity on the market. Nevertheless, the analysis carried out portrayed the PDO/PGI production systems as "living systems", continuously adapting their working rules to the changing local conditions and external settings $[7,9,14,30,31]$.

The empirical base showed that $72 \mathrm{PDO} / \mathrm{PGI}$ products (out of the 379 registered products in the class fruit and vegetables until 31 December 2018) amended their PSs. Most modifications affected the farming practices, with special reference to the plant varieties, productivity and the timing of the practices. Concerning plant varieties, producers normally increased their number to adapt to both the changed climatic conditions, and to market demand. For instance, the legislation for monitoring seed quality and varietal registration, envisaged for supporting the increase in productivity in postwar years, has converted into the limited conservation and development of diverse local varieties and small seed companies [32]. Kader [33] (p. 1863) argued, "New cultivars of fruits and vegetables with better flavor and nutritional quality are being and will likely continue to be developed using both plant breeding methods and biotechnology, especially for commodities for which easily monitored markers of good flavor and/or nutritional quality are identified". This implies that PDO/PGI producers also face the opportunity of new varieties with improved characteristics. None of the modifications explicitly considered the need to preserve the local landraces and agro-biodiversity. Rather, it seemed that local varieties were not the main concern of the amended PSs, not being at the basis of the link 
between the quality and territory [19]. In only a couple of cases was the inclusion of new varieties meant to reduce the use of inputs (water, chemical fertilizers and pesticides), and to favor the adoption of environment-friendly practices. Today's fruit and vegetable production is often based on new and homogenous hybrid varieties inspired by market trends and production intensification, and this is reflected in PDO/PGI products, too [34].

With respect to productivity, most amendments resulted in more flexible rules, which promised increased production potential, often justified by the availability of new technologies and production techniques, thus allowing for the intensification of the production system.

Only three French amendments specifically tightened the use of chemicals. Moser et al. [35,36] argued that consumers would be willing to pay more for fruit which were produced with less or no pesticide use; however, taste might prevail as the main attribute for fruit consumption, as in the case of the Melocotón de Calanda [36,37]. It is well known that the nutritional benefits associated with fruit and vegetables can be lost if the produce is contaminated with pesticides [38]. Likewise, the excess use of fertilizers and pesticides is a source for groundwater contamination [39]. Therefore, it is of great relevance that PDO/PGI producers consider the adoption of agricultural production practices that minimize the effects on the local resources (e.g., water, soil) [7,26,40], or even the adoption of organic production (four of the 81 amendments). Finally, the more flexible rules on the timing of practices were mainly justified by climate change, which has altered the usual development of farming practices over the year and made them less predictable.

All amendments changed some product quality characteristics, but just a few of them specifically modified the rules for environmental reasons. Most of these changes in final product characteristics were justified with evolving demand from customers and final consumers. Most changes about the product quality aimed at making the PS rules more flexible, while there was a certain trend to set more severe rules regarding the ancillary (although important) dimensions such as packaging, labelling, and traceability systems.

When considering the amendments where producers explicitly referred to environment-related considerations ( $25 \%$ of the amendments), half of these can be interpreted as adapting the PSs in reaction to climate and weather change. Indeed, the Food and Agriculture Organization of the United Nations (FAO) warns of climate change resulting in more variable precipitation, droughts and floods affecting future yield and leaving high uncertainties for future food production [40]. Due to climate change, compliance with the PSs might be more difficult to attain. For the continued viability of the PDO/PGI systems, holders shall find approaches to adapt. The need to adjust will be imperative when "the productivity of the geographic area declines sufficiently that livelihoods are threatened" [7] (p. 93). Safeguarding PDO/PGI products against climate change is a relatively new and dynamic issue not fully discussed in the international arena. The innovation and adaptation due to climate change is likely to happen as long as the authenticity, and not "antiquity", of the PDO/PGI products is not altered [41].

The analysis of amendments showed how the technological advances and the research progress may enhance climate adaptation (e.g., the development of varieties more resistant to pests), although in some cases the underlying motivations might be more related to short-term economic goals, especially linked to meeting market demand. Reactive modifications were normally making PS rules more flexible, to give producers additional alternatives for tackling the changed environment. Most modifications (timing, production area) did not seem to significantly alter the link between the quality and the territory at the basis of product specificity, rather the opposite: in order to keep the link, there is the need to adapt the rules to obtain the same results with regards to the final product quality.

On the other side, the analysis pointed out how some amendments contained modifications specifically aimed at proactively enhancing the environment-friendly farming practices or nature, and landscape conservation - up to modifying some PS rules to ease the way for including the organic production method under the PDO/PGI umbrella. The group of proactive amendments was driven by the aim to reduce negative environmental externalities in the production area, with a special emphasis on more sustainable farming practices, achieved by reducing inputs in general and 
chemical ones specifically, and by caring for the quality of soils. Of particular interest within the environmentally proactive amendments were the (few) modifications that involved, as justification, the need to preserve landscape, acknowledged as an important resource for tourism attraction in connection with the product.

Almost all the environmentally justified modifications, taken together with other modifications in the same amendment document, led to a more flexible PS, where the significance of the single environment-driven modification was low compared to the whole amendment.

In general, all the modifications justified with environmental reasons seemed cautious in imposing rules. Rather, they aimed at opening the possibility to reduce the impact on the environment. For example, these modifications did not set limits to pollution, nor oblige to adopt specific environment-friendly farming practices; rather, they allowed for practices that may have a lower impact on the environment. Although acknowledging the importance of these steps towards a higher care for the environment, this trend still seems a bit "weak", while the real motivations behind the modifications appeared rather to be ranging from meeting market demand to competitiveness and cost reduction, and from technological updating to preserving the identity and quality of the final product. This result seems coherent with the findings of Coppola and Ianuario [42] (p. 1741) studying the involvement in ethical and environmental actions by producer organizations in the fruit and vegetable sector in Italy. "Product quality improvement often goes with the promotion of environmentally friendly techniques, while other environmental actions respond to a reduction of costs rather than to a sustainability strategy".

This study was based on document analysis and interpretive reflections within the research team. Therefore, it may be affected by a certain degree of subjectivity in both the classification and the interpretation of the modifications, especially for those amendments where clearly stated justifications were lacking (before 2016 producers were not obliged to motivate amendments in their applications), and in cases where the research team had to "weight" divergent directions of several modifications to state the whole amendment directionality (whether more or less flexible). Studies for other product categories and more in-depth analysis on single case studies are needed to further grasp the direction of the PDO/PGI amendments, the factual motivations behind those stated in official documents and the context-specific, sometimes conflictual strategies adopted by producer groups.

\section{Conclusions}

There is a worldwide pressing need to adopt more environment-friendly agro-food production systems, focusing on areas such as genetic resource and biodiversity conservation or the protection of soil and water (e.g., via integrated ecological pest, soil, or water management) $[43,44]$.

The protection of geographical indications is growingly advocated to support not only economic but also social and environmental sustainability [45]. Indeed, environmental stewardship has frequently been evoked by policy makers and value-chains actors as a justification for protection [46,47]. Although the protection of geographical indications in the EU has not been conceived as a means to enhance environmental protection [48], the debate about the opportunity to charge the PDO/PGI protection with this new task has emerged, especially during the discussion of the Green Paper on Quality Policy in 2008, where this question was asked for stakeholders' consultation: "Should specific sustainability and other criteria be included as part of the specification, whether or not they are intrinsically linked to origin? What would be the benefits and drawbacks?" [49] (Question 6, p. 13). The consultation reported the following result $[48,50]$ : a large majority of respondents from different sectors, with the exception of national authorities and individual consumers/farmers, were opposed to specific sustainability and other criteria. Among the number of those who expressed against such criteria, the main disadvantages mentioned were the risk of consumer confusion and the risk of a reduction of benefits. Respondents in favor underlined as main advantages better consumer information, or the need to introduce environmental criteria. 
As of yet, EU legislation does not mention environmental concerns among its scope. Thévenod-Mottet [46] noted that the concerns for the environment and biodiversity were not explicitly addressed in any national requirement for GI protection, but acknowledged their potential for acquiring new dimensions as policy instruments.

While EU policy makers and many producers show resistance to introducing compulsory environmental rules for the PDO/PGI products [51], some local actors seem to be becoming more aware of the interdependence between their products and the local environment [27,52]. Nonetheless, it seems that short-term goals may prevail over the search for environmental sustainability, and the environment is not (yet) fully part of the PDO/PGI producers' strategies. Indeed, our study showed that technological advances and market-driven reasons were the most stated justifications for amending rules for this product class, while environment-related motivations played a minor role.

Only a few amendments contained modifications explicitly justified by environmental reasons and landscape conservation, although producers mostly mobilized the environment as an instrument to achieve a competitive advantage, while positioning the product on the market (new consumers' habits, customer requests, cost reduction, quality and identity of the product). The majority of the amendments resulted in more flexible PS rules, France being the only country also tightening a considerable share of rules. The main goal for producers was market competitiveness, so why should they add environmental rules in the PS, without a direct or indirect economic benefit? In only some cases where the PDO/PGI product is part of a wider territorial strategy, could there be a higher attention to environmental preservation, thus supporting multifunctional production systems.

These outcomes are quite in line with the general scope of PDO/PGI protection, also according to what is stated in the EU Regulations, which do not mention the environment as a possible objective of protection, thus being rather conceived of as a marketing tool. Although the EU PDO/PGI legislation does not stipulate the inclusion of specific environmental rules in the PS, the debate on the "greening" of the EU protection was not new [26,41,46]. Perhaps policy makers and related stakeholders should follow new approaches to address this issue. Rather than convincing the PDO/PGI producers to introduce explicit (mandatory) environmental rules, policy makers might concentrate on further linking the product to territorial specificities and local biodiversity, identity and quality. Indeed, Ricchieri et al. [26] used the term environmental quality clauses for preserving the resources at the basis of product specificity. Two different philosophies seem to emerge: one more focused on the material quality characteristics of the product, while others are more sensitive to the characteristics of the production process and of local traditions and varieties (extrinsic or symbolic quality characteristics).

Author Contributions: A.M., X.F.Q.-R., H.E., G.B., K.B., C.A., M.P., and S.S. jointly elaborated the conceptual framework, the methodology, and data analysis and interpretation. All authors have read and agreed to the published version of the manuscript.

Funding: This project is supported by funds of the Oesterreichische Nationalbank (Austrian National Bank, Anniversary Fund, Project Number: 17043) coordinated by Marianne Penker, and by funds of the University of Florence (IT), research project "Tutela e valorizzazione dei prodotti agro-alimentari basati su risorse genetiche autoctone" (years 2017-2018), coordinated by Andrea Marescotti.

Acknowledgments: The authors wish to thank Christina Roder for the editorial support; moreover, the authors are thankful for the valuable comments from anonymous reviews. Open access funding provided by BOKU Vienna Open Access Publishing Fund.

Conflicts of Interest: The authors declare no conflict of interest.

\section{References}

1. Regulation (EU) No 1151/2012 of the European Parliament and of the Council of 21 November 2012 on quality schemes for agricultural products and foodstuffs. OJ L 2012, 343, 1-29.

2. Bérard, L.; Marchenay, P. Local products and geographical indications: Taking account of local knowledge and biodiversity. Int. Soc. Sci. J. 2006, 58, 109-116. [CrossRef] 
3. Belletti, G.; Marescotti, A. Origin products, geographical indications and rural development. In Labels of Origin for Food: Local Development, Global Recognition; Barham, E., Sylvander, B., Eds.; CABI: Wallingford, UK, 2011; pp. 75-91.

4. Bowen, S.; Mutersbaugh, T. Local or localized? Exploring the contributions of Franco-Mediterranean agrifood theory to alternative food research. Agric. Hum. Values 2014, 31, 201-213. [CrossRef]

5. Arfini, F.; Cozzi, E.; Mancini, M.C.; Ferrer-Perez, H.; Gil, J.M. Are geographical indication products fostering public goods? Some evidence from Europe. Sustainability 2019, 11, 272. [CrossRef]

6. Clark, L.F.; Kerr, W.A. Climate change and terroir: The challenge of adapting geographical indications. J. World Intellect. Prop. 2017, 20, 88-102. [CrossRef]

7. Arfini, F.; Antonioli, F.; Cozzi, E.; Donati, M.; Guareschi, M.; Mancini, M.C.; Veneziani, M. Sustainability, Innovation and Rural Development: The Case of Parmigiano-Reggiano PDO. Sustainability 2019, 11, 4978. [CrossRef]

8. Conneely, R.; Mahon, M. Protected geographical indications: Institutional roles in food systems governance and rural development. Geoforum 2015, 60, 14-21. [CrossRef]

9. Bérard, B.; Casabianca, F.; Montel, M.C.; Agabriel, C.; Bouche, R. Salers Protected Designation of Origin cheese, France. The diversity and paradox of local knowledge in geographical indications. Cult. Hist. Dig. J. 2016, 5. [CrossRef]

10. Bromberg, B.E. Aged, but not old: Local identities, market forces, and the invention of 'traditional' European cheeses. In Authenticity in the Kitchen, Proceedings of the Oxford Symposium on Food and Cookery 2005; Hosking, R., Ed.; Prospect Books: Devon, UK, 2006; pp. 89-102.

11. Arfini, F.; Capelli, M.G. The resilient character of PDO/PGI products in dynamic food markets. In Proceedings of the 113th EAAE Seminar, A Resilient European Food Industry and Food Chain in a Challenging World, Chania, Greece, 3-6 September 2009. Available online: https://ideas.repec.org/p/ags/eaa113/57670.html (accessed on 16 October 2019).

12. Barjolle, D.; Jeanneaux, P. Raising rivals' costs strategy and localised agro-food systems in Europe. Int. J. Food Syst. Dyn. 2012, 3, 11-21. [CrossRef]

13. Dentoni, D.; Menozzi, D.; Capelli, M.G. Group heterogeneity and cooperation on the geographical indication regulation: The case of the "Prosciutto di Parma" Consortium. Food Policy 2012, 37, 207-216. [CrossRef]

14. Quiñones-Ruiz, X.F.; Forster, H.; Penker, M.; Belletti, G.; Marescotti, A.; Scaramuzzi, S.; Broscha, K.; Braito, M.; Altenbuchner, C. How are food geographical indications evolving?-An analysis of EU GI amendments. Br. Food J. 2018, 120, 1876-1887. [CrossRef]

15. Quetier, F.; Marty, P.; Lepart, J. Farmers' management strategies and land use in an agropastoral landscape: Roquefort cheese production rules as a driver of change. Agric. Syst. 2005, 84, 171-193. [CrossRef]

16. Gueringer, A.; Orth, D.; Balay, C.; Landre, F. Contribution of different farming and forage systems to biodiversity: An example in a PDO cheese area in French mountains. In Proceedings of the Building Sustainable Rural Futures-The Added Value of Systems Approaches in Times of Change and Uncertainty, 9th European IFSA Symposium, 4-7 July 2010, Vienna Austria; Darnhofer, I., Grötzer, M., Eds.; University of Natural Resources and Applied Life Sciences: Vienna, Austria, 2010; pp. 1740-1748. Available online: http://ifsa.boku.ac.at/cms/index.php?id=111\#c282 (accessed on 16 October 2019).

17. Colinet, P.; Desquilbet, M.; Hassan, D.; Monier-Dilhan, S.; Orozco, V.; Réquillart, V. Case study: Comté Cheese in France. INRA, University of Toulouse, 2006. Available online: https://ec.europa.eu/agriculture/ sites/agriculture/files/quality/certification/docs/case3_en.pdf (accessed on 16 October 2019).

18. Arfini, F.; Bellassen, V. (Eds.) Sustainability of European Food Quality Schemes: Multi-Performance, Structure, and Governance of PDO, PGI, and Organic Agri-Food Systems; Springer Nature: Basel, Switzerland, 2019. [CrossRef]

19. Morris, C.; Kirwan, J. Ecological embeddedness: An interrogation and refinement of the concept within the context of alternative food networks in the UK. J. Rural Stud. 2011, 27, 322-330. [CrossRef]

20. Biénabè, E.; Leclerq, M.; Moity-Maizi, P. Le Rooibos d'Afrique du Sud: Comment la biodiversité s'invite dans la construction d'une indication géographique. Autrepart 2009, 50, 117-134. [CrossRef]

21. Lamarque, P.; Lambin, E.F. The effectiveness of marked-based instruments to foster the conservation of extensive land use: The case of geographical indications in the French Alps. Land Use Policy 2015, 42, 706-717. [CrossRef]

22. Guerra, J.L. Geographical indications and biodiversity: Bridges joining distant territories. Bridges 2004, 8, 17. 
23. Blakeney, M. Geographical indications and environmental protection. Front. Law China 2017, 2, $162-173$. [CrossRef]

24. Bowen, S.; Valenzuela Zapata, A. Geographical indications, terroir, and socioeconomic and ecological sustainability: The case of tequila. J. Rural Stud. 2009, 25, 108-119. [CrossRef]

25. European Commission. DOOR Database, 2014. Available online: http://ec.europa.eu/agriculture/quality/ door/list.html (accessed on 31 December 2018).

26. Riccheri, M.; Görlach, B.; Schlegel, S.; Keefe, H.; Leipprand, A. Assessing the Applicability of Geographical Indications as a Means to Improve Environmental Quality in Affected Ecosystems and the Competitiveness of Agricultural Products; Workpackage 3, Final Report; IPDEV: Paris, France, 2007. Available online: https: //ideas.repec.org/p/ess/wpaper/id847.html (accessed on 16 October 2019).

27. Larson, J. Relevance of Geographical Indications and Designations of Origin for the Sustainable Use of Genetic Resources; Global Facilitation Unit for Underutilized Species: Rome, Italy, 2007.

28. Belletti, G.; Canada, J.S.; Marescotti, A.; Vakoufaris, H. Linking protection of geographical indications to the environment: Evidence from the European Union olive-oil sector. Land Use Policy 2015, 48, 94-106. [CrossRef]

29. Tansey, G.; Worsley, T. The Food System-A Guide; Earthscan: London, UK, 1995.

30. Belletti, G.; Marescotti, A.; Touzard, J.M. Geographical indications, public goods and sustainable development: The roles of actors' strategies and public policies. World Dev. 2015, 98, 45-57. [CrossRef]

31. Belmin, R.; Casabianca, F.; Meynard, J.M. Contribution of the transition theory to the study of geographical indications. Environ. Innov. Soc. Transit. 2018, 27, 32-47. [CrossRef]

32. Visser, B. An agrobiodiversity perspective on seed policies. In Seed Policy, Legislation and Law: Widening a Narrow Focus; Louwaars, N.P., Ed.; Food Products Press: Binghamton, NY, USA, 2002; pp. 231-246.

33. Kader, A.A. Flavor quality of fruits and vegetables. J. Sci. Food Agric. 2008, 88, 1863-1868. [CrossRef]

34. Boisvert, V. From the Conservation of Genetic Diversity to the Promotion of Quality Foodstuff: Can the French Model of 'Appelation d'Origine Controlee' be Exported? CAPRI Working Paper No. 49; Environmental and Production Technology Division, International Food Policy Research Institute (IFPRI): Washington, DC, USA, 2006.

35. Moser, P.; Raffaelli, R.; McFadden, D.T. Consumer preferences for fruit and vegetable with credence - based attributes: A review. Int. Food Agribus. Manag. Rev. 2011, 14, 121-142.

36. Groot, E.; Albisu, L.M. Preferencias de los consumidores regulares y esporádicos de melocotones de la DOP "Melocotón de Calanda". Inf. Tec. Econ. Agrar. 2016, 112, 336-351. [CrossRef]

37. Bruhn, C.M. Consumer and retailer satisfaction with the quality and size of California peaches and nectarines. J. Food Qual. 1995, 18, 241-256. [CrossRef]

38. Keatinge, J.D.H.; Yang, R.-Y.; Hughes, J.d.A.; Easdown, W.J.; Holmer, R. The importance of vegetables in ensuring both food and nutritional security in attainment of the Millennium Development Goals. Food Sec. 2011, 3, 491-501. [CrossRef]

39. Bouwer, H. Agricultural chemicals and ground water quality-Issues and challenges. Groundw. Monit. Remediat. 1990, 10, 71-79. [CrossRef]

40. Food and Agriculture Organization of the United Nations (FAO). The Future of Food and Agriculture. Trends and Challenges; Food and Agriculture Organization of the United Nations (FAO): Rome, Italy, 2017. Available online: http://www.fao.org/3/a-i6583e.pdf (accessed on 17 October 2019).

41. Mattei, F. Integrating adaptation strategy to climate change into geographical indication protection. Available online: https:/www.rouse.com/magazine/news/integrating-adaptation-strategy-to-climatechange-into-geographical-indication-protection/ (accessed on 11 October 2019).

42. Coppola, A.; Ianuario, S. Environmental and social sustainability in producer organizations' strategies. Br. Food J. 2017, 119, 1732-1747. [CrossRef]

43. Thrupp, L.A. Linking agricultural biodiversity and food security: The valuable role of agrobiodiversity for sustainable agriculture. Int. Aff. 2000, 76, 283-297. [CrossRef]

44. Reynolds, C.R.; Buckley, J.D.; Weinstein, P.; Boland, J. Are the dietary guidelines for meat, fat, fruit and vegetable consumption appropriate for environmental sustainability? A review of the literature. Nutrients 2014, 6, 2251-2265. [CrossRef]

45. Vandecandelaere, E.; Arfini, F.; Belletti, G.; Marescotti, A. Linking People, Places and Products. A Guide for Promoting Quality Linked to Geographical Origin and Sustainable Geographical Indications, 2nd ed.; Food and Agriculture Organization of the United Nations (FAO) and SINER-GI: Rome, Italy, 2010. 
46. Thévenod-Mottet, E. Geographical indications and biodiversity. In Agriculture, Biodiversity and Markets; Lockie, S., Carpenter, D., Eds.; Earthscan: London, UK, 2010; pp. 201-212.

47. Marie-Vivien, D.; Chabrol, D. Geographical Indications, Biodiversity and Poor Communities: The Opportunity of Geographical Indications to Provide Protection of Traditional Indigenous Biodiversity Products and Benefits to Poor Agricultural Communities; A Desk Study on Six Target Countries: Cambodia, Laos, Indonesia, Vietnam, Ethiopia, Mauritania; UNCTAD (United Nations Conference on Trade and Development): Geneva, Switzerland; CFF (Crop For the Future): Serdang, Malaysia, July 2014.

48. European Commission. Impact Assessment Report for a Communication on Agricultural Product Quality Policy; Annex B Geographical Indications. Version 08-4-09; European Commission: Brussels, Belgium, 2009. Available online: https://ec.europa.eu/agriculture/quality/policy/com2009_234/ia_annex_b_en.pdf (accessed on 16 October 2019).

49. European Commission. Green Paper on Agricultural Product Quality: Product Standards, Farming Requirements and Quality Schemes; European Commission: Brussels, Belgium, 2008. Available online: https://op.europa. eu/en/publication-detail/-/publication/5b0882f5-55f7-41b5-af74-296820b1030f/language-en (accessed on 16 October 2019).

50. European Commission. Conclusions from the Consultation on Agricultural Product Quality; VC D (2009) Directorate-General for Agriculture and Rural Development, European Commission: Brussels, Belgium, 2009.

51. Ansaloni, A.; Fouilleux, E. Terroir et protection de l'environnement: Un mariage indésirable? Polit. Manag. Public 2008, 26, 4-24. [CrossRef]

52. Giovannucci, D.; Josling, T.; Kerr, W.; O'Connor, B.; Yeung, M.T. Guide to Geographical Indications. Linking Products and Their Origin; International Trade Center: New York, NY, USA, 2009.

(C) 2020 by the authors. Licensee MDPI, Basel, Switzerland. This article is an open access article distributed under the terms and conditions of the Creative Commons Attribution (CC BY) license (http://creativecommons.org/licenses/by/4.0/). 